\title{
Pérenniser la reprise irlandaise pour tous
}

Écrit par : Angel Gurría, Secrétaire général de l’OCDE

Dernière mise à jour : 3 janvier 2016

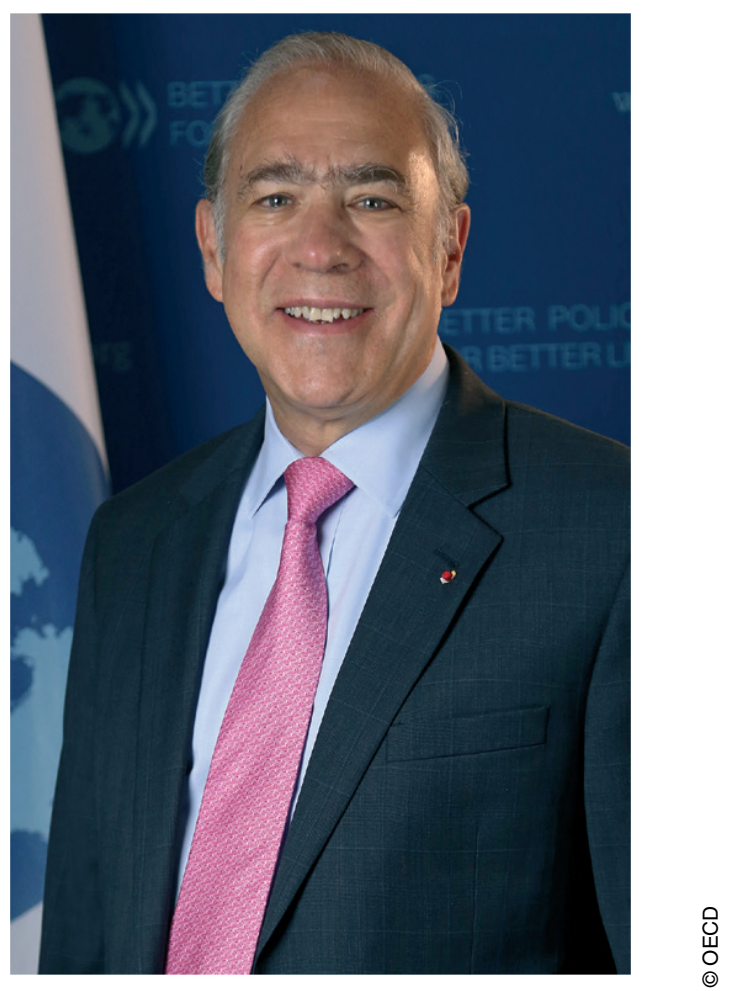

Lors de ma présentation de l'Étude économique 2011, l'économie irlandaise connaissait les affres d'une profonde récession. Depuis deux ans, les perspectives se sont éclaircies. Je suis ravi aujourd'hui de voir à quel point et à quelle cadence le pays a su rebondir.

L'économie prospère et connaît la plus rapide croissance de la zone OCDE. La vie des citoyens s'en trouve nettement améliorée, et les séquelles sociales de la crise commencent à s'atténuer. Le chômage, qui avait dépassé les 15 \%, est retombé audessous de $10 \%$, l'économie crée plus de 1000 emplois par semaine, la plupart à temps plein, et les salaires moyens augmentent. Avec l'amélioration du marché du travail, l'émigration nette est redescendue à un tiers du sommet atteint en 2012.

La détermination des pouvoirs publics à réformer y est pour beaucoup. Le système bancaire a été restructuré et recapitalisé, le déficit budgétaire sensiblement réduit, la dette publique placée sur une trajectoire baissière, l'efficience de 
l'administration publique accrue, et les services publics de l'emploi réorganisés. L'Irlande va indiscutablement dans la bonne direction!

Il faut maintenant pérenniser la reprise, pour faire en sorte que tous profitent de la prospérité retrouvée et pour renforcer la résilience face aux défis à venir. L'investissement étranger a longtemps été la pierre angulaire des secteurs dynamiques que sont les TI, le matériel médical, l'industrie pharmaceutique et les services financiers. Les « Silicon Docks » à Dublin, pôle de pointe des TI, abritent le siège européen des plus grands noms de l'économie numérique mondiale.

En revanche, les petites et moyennes entreprises (PME) irlandaises continuent d'accuser un retard, ramenant la croissance de la productivité globale à seulement 0,5\% par an - soit un quart du niveau de l'année 2000. Pour relancer la productivité, les pouvoirs publics doivent mieux accompagner la diffusion des connaissances et de l'innovation technologique du secteur extérieur aux PME nationales. Le soutien financier à l'innovation devrait être rééquilibré et délaisser les incitations fiscales - souvent mieux adaptées aux multinationales - au profit d'un financement direct, plus accessible aux petites entreprises. Des mesures devraient être prises pour que toutes les entreprises accèdent au réservoir mondial de talents.

Pour que tous ces éléments convergent, la productivité doit bénéficier d'une approche pangouvernementale. Mais l'amélioration de la productivité et la croissance économique ne sauraient constituer des fins en soi. Le relèvement durable du niveau de vie des citoyens doit être l'objectif primordial. L'Irlande a traversé sept années difficiles pour remettre son économie sur les rails et ses finances publiques en ordre.

Les contributions de ménages plus aisés ont progressivement augmenté et les prestations sociales de base aux retraités et aux chômeurs ont pu être largement protégées. Il faut observer que le système irlandais de prélèvements et transferts est celui des pays de l'OCDE qui parvient le mieux à réduire les inégalités.

C'est en matière d'activation du marché du travail que les plus grandes avancées sont à noter. Les pouvoirs publics ont su transformer un système social globalement passif en un système où la première journée où l'on bénéficie d'allocations marque la première étape vers le retour au travail.

Mais des défis subsistent. Encore environ 120000 personnes sont sans emploi depuis plus d'un an. Nombreux sont ceux qui manquent des compétences nécessaires pour participer à la reprise; il serait donc opportun de repenser le système d'apprentissage.

Il faudrait également en faire davantage pour en finir avec le chômage et les pièges de la pauvreté. Il arrive parfois que l'aide financière - allocation logement ou complément de revenu familial - soit retirée trop vite avec l'augmentation du revenu. Par ailleurs, la garde des enfants représente $40 \%$ du salaire moyen, le 
pourcentage le plus élevé des pays de l'OCDE. Il faut donc œuvrer à rendre plus abordables les services de garde d'enfants, notamment pour les familles à revenus faibles.

Dans le cas de l'Irlande, assurer une reprise inclusive signifie également contenir plus encore l'émigration, en s'attachant à faire revenir ceux qui sont partis ces dernières années, et à mieux intégrer ceux qui sont arrivés depuis le début du siècle et qui continuent d'arriver en nombre relativement élevé.

Qu'il s'agisse des émigrés ou des immigrés, cette population se caractérise par un niveau d'instruction élevé. Plus de la moitié a un niveau post-secondaire.

L'Irlande doit faire mieux pour inciter les émigrés à rentrer, après leur expérience internationale, et pour intégrer les immigrés qualifiés dans le marché du travail national.

L'Irlande est de nouveau dans le peloton de tête des économies de l'OCDE. Dans les mois et années à venir, l'enjeu consistera à faire en sorte que la reprise soit durable et inclusive. L'OCDE

L'Irlande est de nouveau dans le peloton de tête des économies de l'OCDE. est prête à travailler aux côtés de l'Irlande à chaque étape, pour concevoir et mettre en œuvre des politiques meilleures pour une vie meilleure.

CL'Observateur de l'OCDE n³05, T1 2016

Extrait adapté de l'allocution prononcée à Dublin lors du lancement d'Études économiques de l'OCDE : Irlande, 15 septembre 2015. Les données peuvent avoir changé depuis cette allocution. Lire le discours entier : le texte intégral. Voir aussi http://www.oecd.org/fr/irlande/ 